\title{
The Impact of Dairy Elimination on Pediatric Atopic Dermatitis
}

\author{
Aleksandra Nikolovski and Stefan Rallis*
}

Dr. Rallis Wellness Group, Ontario, Canada

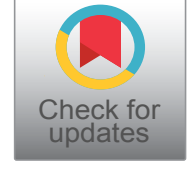

*Corresponding author: Dr. Stefan Rallis, Dr. Rallis Wellness Group, 470 Big Bay Point Road, Barrie, Ontario, L4N 3Z4, Canada, Tel: 705-733-3484, Fax: 705-733-3997

\begin{abstract}
Atopic dermatitis (AD) is a relatively common, inflammatory skin condition of variable severity. Known food allergens such as dairy may play a role in the exacerbation of this T-cell mediated autoimmune condition. A four-year-old patient with severe, non-resolving $A D$ was placed on a dairyfree elimination diet. Quantitative analysis included the use of the Hanifin and Rajka diagnostic tool and the Scoring Atopic Dermatitis Calculator (SCORAD). The patient demonstrated a $76 \%$ improvement in her symptoms within 10 days of eliminating dairy products from her diet, illustrated by a SCORAD reduction from 70.9 to 16.7 . A further $30 \%$ relative SCORAD improvement of $16.7 / 100$ to $11.6 / 100$ was demonstrated at the patient's four-month follow-up. Potential food allergens such as cow's milk and other dairy products should be considered as potential inflammatory mediators of this dermatological condition.
\end{abstract}

\section{Keywords}

Atopic dermatitis, Dairy, Cow's milk, IgG

\section{Introduction}

Atopic dermatitis (AD) is a chronic, inflammatory skin disease affecting up to $20 \%$ of children [1]. Characterized by the presence of pruritis and elevated skin lesions, $A D$ is a T-cell mediated autoimmune condition resulting in elevated levels of inflammatory cytokines such as IL-9, IL-17 and IL-22 [2]. This inflammatory cascade is both IgE and IgG-mediated [3]. Dermatological literature consistently identifies potential correlations between intake of cow's milk products, elevations in IgG levels, and aggravation of $A D$ in children $[3,4]$. Consequently, the elimination of cow's milk and milk products can often result in a reduction in inflammatory cytokines [5] and the potential improvement in childhood AD.

\section{Case Report/Case Presentation}

A 4-year-old, Caucasian female presented with severe, non-resolving atopic dermatitis on both legs, upper extremities, abdomen, and back. The onset of the disease occurred at 3.5 years of age, beginning with an elevated, pruritic lesion of $3 \mathrm{~cm}$ in diameter on her posterior thigh. This was followed by further elevated lesions on her arms and back, which were also pruritic. The patient's family physician initially diagnosed the lesions as pityriasis rosea, and recommended the use of Benadryl. With little relief and progressive exacerbations over 6 weeks, the patient was diagnosed with eczema at a walk-in clinic, followed by atopic dermatitis $(A D)$, by an emergency room physician. The latter diagnosis was confirmed by a pediatric dermatologist four months after her initial visit with her family physician. The severity of her AD continued to increase, with progressive lichenification, oozing, and crusting, requiring bandaging of the lower extremities. She was prescribed hydrocortisone cream, advised to minimize her time in the water, and instructed to use unscented detergents. Daily use of topical hydrocortisone and adherence to environmental modifications over 4-6 months provided only marginal relief, with severe intermittent exacerbations persisting.

The patient first attended our clinic on March 5, 2019 seeking an alternative primary care perspective on her case. A dermatological examination revealed severe erythema, swelling, crusting, and lichenification (Figure 1). The patient fulfilled 3 major and 4 minor criteria on the Hanifin and Rajka Diagnostic Criteria for Atopic Dermatitis [6]. To quantify the severity of the condition, the Scoring Atopic Dermatitis Calculator (SCORAD), developed by the European Task Force on Atopic Dermatitis

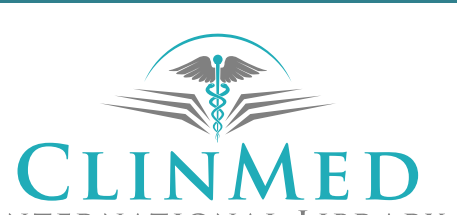

INTERNATIONAL LIBRARY 


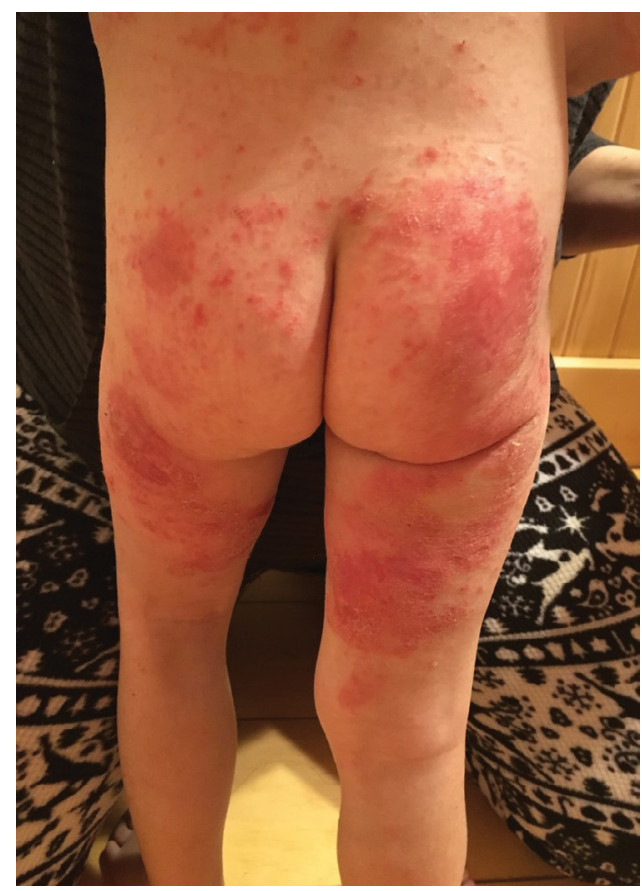

Figure 1: Exacerbation at initial assessment (March 5, 2019).

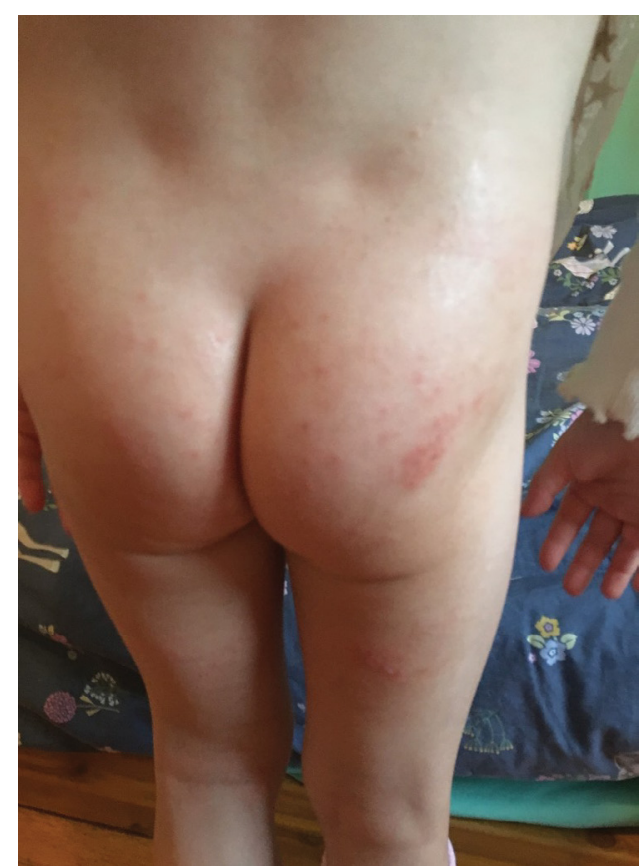

Figure 2: Reduction in symptoms after 10-day dairy elimination.

was used, which assesses severity of three domains: Extent or breadth, intensity, and subjective symptoms including itchiness and sleep loss $[7,8]$. The patient's overall condition severity was quantified as 70.9 out of 100 using the SCORAD assessment. The patient's diet was also assessed as part of her initial examination. Her diet consisted of a minimum of 2 servings of dairy per day, most commonly in the form of cheese, milk, or yogurt. Breakfast consisted of waffles or pancakes with a glass of chocolate milk and fruit. Lunch consisted of vegetables, fruit, and yogurt, and dinner included pasta, meat, and occasional dairy-based sauce or seasoning. The pa-

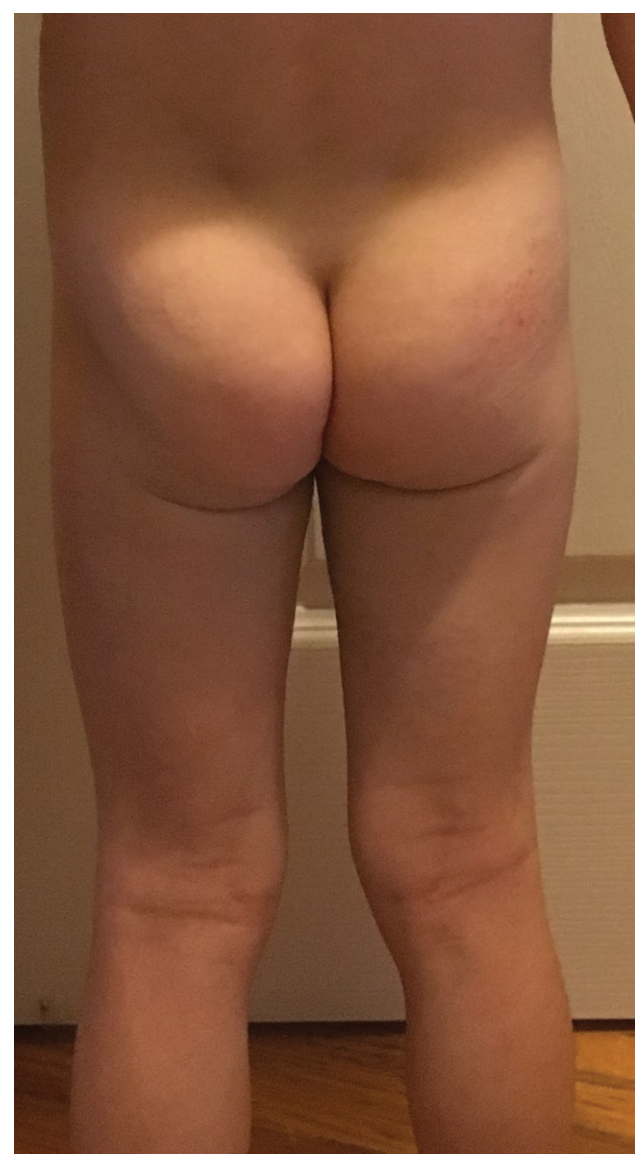

Figure 3: Reduction in symptoms at four-month follow-up.

tient often consumed milk-based ice-cream for dessert.

A modified elimination diet was prescribed which included the elimination of dairy. A follow-up was scheduled 10 days later, at which time the patient demonstrated dramatic improvement (Figure 2). A follow-up SCORAD was also conducted which demonstrated a $76.4 \%$ improvement, with a SCORAD rating of 16.7 out of 100 . Due to the significant improvement in dermatitis, it was suggested that the patient re introduce dairy to her diet to affirm the correlation. The patient re introduced dairy and noted severe exacerbation, reporting a pruritus rating of 9 out of 10 and the presence of broken skin, lichenification, and swelling, all of which was relieved with a secondary elimination. A 4-month follow-up after the initial elimination illustrated further improvement with a SCORAD rating of 11.6 out of 100 (Figure 3). Table 1 illustrates the progressive improvements, including the relapse during, and the remission after dairy was reintroduced. At the 4-month follow-up appointment, the patient reported $95 \%$ compliance with dairy elimination, with the exception of fewer than 5 occurrences when dietary accommodation was unavailable. On these occasions, the patient reported increases in pruritus from from 0 to a 7 out of 10, lasting for 2-3 days following dairy consumption.

\section{Discussion/Conclusion}

The patient demonstrated dramatic improvement in 
Table 1: SCORAD rankings at intake, 10-day follow-up, dairy reintroduction and 4-month follow up.

\begin{tabular}{|c|c|c|c|c|}
\hline Date & Extent (Region) & Intensity $(0,1,2,3)$ & Subjective Rating (0-10) & Total Score/100 \\
\hline $\begin{array}{l}\text { Intake Exam: } \\
\text { March 5, } 2019\end{array}$ & $\begin{array}{l}\text { Score: } 72 \\
\text { 1) Legs: anterior and } \\
\text { posterior } \\
\text { 2) Arms: anterior and } \\
\text { posterior } \\
\text { 3) Back and glutes }\end{array}$ & $\begin{array}{l}\text { Score: } 11 \\
\text { Erythema (3) } \\
\text { Edema (2) } \\
\text { Oozing/crusting (2) } \\
\text { Excoriation (1) } \\
\text { Lichenification (1) } \\
\text { Dryness (1) }\end{array}$ & $\begin{array}{l}\text { Score: } 18 \\
\text { Pruritus (9) } \\
\text { Sleep loss (9) }\end{array}$ & 70.9 \\
\hline $\begin{array}{l}\text { 10-day Follow-up: } \\
\text { March 15, } 2019\end{array}$ & $\begin{array}{l}\text { Score: } \mathbf{3 6} \\
\text { 1) Legs: anterior and } \\
\text { posterior } \\
\text { 2) Glutes }\end{array}$ & $\begin{array}{l}\text { Score: } 2 \\
\text { Erythema (1) } \\
\text { Edema (0) } \\
\text { Oozing/crusting (0) } \\
\text { Excoriation (0) } \\
\text { Lichenification (1) } \\
\text { Dryness (0) }\end{array}$ & $\begin{array}{l}\text { Score: } \mathbf{2 . 5} \\
\text { Pruritus (1.5) } \\
\text { Sleep loss (1) }\end{array}$ & 16.7 \\
\hline $\begin{array}{l}\text { Dairy reintroduction: } \\
\text { March 30-April 1, } 2019 \\
\text { (3 days) }\end{array}$ & $\begin{array}{l}\text { Score: } \mathbf{3 6} \\
\text { 1) Legs: anterior and } \\
\text { posterior } \\
\text { 2) Glutes }\end{array}$ & $\begin{array}{l}\text { Score: } 7 \\
\text { Erythema (2) } \\
\text { Edema (1) } \\
\text { Oozing/crusting (2) } \\
\text { Excoriation (1) } \\
\text { Lichenification (1) } \\
\text { Dryness (0) }\end{array}$ & $\begin{array}{l}\text { Score: } \mathbf{9} \\
\text { Pruritus (9) } \\
\text { Sleep loss }(0)\end{array}$ & 40.7 \\
\hline $\begin{array}{l}\text { 4-month Follow-up: } \\
\text { July } 23,2019\end{array}$ & $\begin{array}{l}\text { Score: } 18 \\
\text { 1) Legs: posterior } \\
\text { 2) Glutes }\end{array}$ & $\begin{array}{l}\text { Score: } \mathbf{2} \\
\text { Erythema (1) } \\
\text { Edema (0) } \\
\text { Oozing/crusting (0) } \\
\text { Excoriation (0) } \\
\text { Lichenification (1) } \\
\text { Dryness (0) }\end{array}$ & $\begin{array}{l}\text { Score: } 1 \\
\text { Pruritus (1) } \\
\text { Sleep loss (0) }\end{array}$ & 11.2 \\
\hline
\end{tabular}

her AD once dairy was eliminated. After multiple forms of intervention including topical creams, steroids, and environmental modifications were deemed ineffective in resolving her case, the elimination of dairy was introduced. This intervention was easy to implement and was deemed both safe and well tolerated, with no adverse events noted. This case further exemplifies the gross underutilization of dietary interventions in the primary care management of most dermatological conditions [9]. This is most likely due to the paucity of research implicating known food allergens such as dairy, eggs, or wheat with inflammatory skin conditions such as AD. Consequently, the full extent of the pathophysiology surrounding the effects of these dietary interventions is lacking. Because AD is partially IgG-mediated, it is reasonable to assume that as the child's immune system matures, she will experience less reactivity to these eliminated food groups. It is our hope that the findings of this case may help propagate further research and may lead primary care providers to consider food sensitivities as potential inflammatory mediators in dermatological conditions such as AD.

\section{Acknowledgement}

There are no acknowledgements to declare. All contributors are authors.

\section{Statement of Ethics}

Informed, written consent for publishing the case including photographs was obtained from the patient and her parents. This research was conducted ethically in accordance with the World Medical Association Declaration of Helsinki.

\section{Disclosure Statement}

The authors declare no conflict of interest.

\section{Funding Sources}

There was no funding of this publication.

\section{Author Contributions}

Clinical interventions and patient care were directed by Dr. Rallis. Outcome assessments and progress reporting was managed by Ms. Nikolovski. Research and authorship, including literature reviews were conducted collaboratively for this case study.

\section{References}

1. Asher MI, Montefort S, Bjorksten B, Lai CK, Strachan DP, et al. (2006) Worldwide time trends in the prevalence of symptoms of asthma, allergic rhinoconjunctivitis, and eczema in childhood: ISAAC phases one and three repeat multicountry cross-sectional surveys. Lancet 368: 733-743.

2. Auriemma M, Vianale G, Amerio $P$, Reale M (2013) Cytokines and T cells in atopic dermatitis. Eur Cytokine Netw 24: 37-44.

3. Liu Y, Yan H, Shao F, Li QH, Cui M (2018) Correlation between childhood eczema and specific IgG antibody level. J Biol Regul Homeost Agents 32: 341-344.

4. Ferguson AC, Salinas FA (1984) Elevated IgG immune complexes in children with atopic eczema. J Allergy Clin Immunol 74: 678-682. 
5. Barros K, Flor Silveira V, Laranjeira M, Wandalsen N, Passeti S, et al. (2017) Evidence for involvement of IL-9 and IL-22 in cows' milk allergy in infants. Nutrients 9: 1048.

6. Bos JD, Van Leent EJ, Smitt JS (1998) The millennium criteria for the diagnosis of atopic dermatitis. Exp Dermatol 7: 132-138.

7. Stalder JF, Barbarot S, Wollenberg A, Holm EA, De Raeve L, et al. (2011) Patient-Oriented SCORAD (PO-SCORAD):
A new self-assessment scale in atopic dermatitis validated in Europe. Allergy 66: 1114-1121.

8. Pourpak Z, Farhoudi A, Mahmoudi M, Movahedi M, Ghargozlou M, et al. (2004) The role of cow milk allergy in increasing the severity of atopic dermatitis. Immunol Invest 33: 69-79.

9. Katta R, Desai SP (2014) Diet and dermatology: The role of dietary intervention in skin disease. $\mathrm{J}$ Clin Aesthet Dermatol 7: 46-51. 